a definite scotoma for green was made out though at times she was not certain even about the red colour.

There was optic atrophy of both discs. Blood vessels were reduced to mere red streaks with white lines along them and beyond the border of the discs they were mere thin white lines. Though the right eye was blind the fundus appearances.were quite similar.

Comments:-Generally the prognosis in quinine amblyopia is good, but in this case though the pallor of both discs is equally marked one eye is blind and it is difficult to give any definite cause for it. However, five years after the onset the left eye has still good vision though her field of vision has remained very much contracted. Another point of interest is the central colour scotoma as a result of which she is particularly embarrassed while doing her near work. This rare phenomenon was reported by Galezowski, de Wecker, Jodko, Bietti and Edgar Smith and this was found mentioned in Ball's Modern Ophthalmology on page 890. The presence of a central colour scotoma seems to support one of the theories that quinine-directly attacks ganglion cells of the retina and this leads to ascending degeneration of the nerve fibres of the optic nerve. But it seems quite probable that the degeneration of nerve fibres is primarily due to lack of circulation.

\title{
TREPHINING IN THE TREATMENT OF CONGENITAL GLAUCOMA
}

BY

\author{
Lt.-Col. R. E. Wright, C.I.E., M.D., I.M.S. \\ AND \\ K. Koman Nayar, L.R.C.P. \& S., D.O.M.S. \\ GOVERNMENT OPHTHALMIC HOSPITAL, MADRAS, INDIA
}

THIs condition is not uncommonly met with here in all its phases; about three or four cases a year are seen by the writers. In common with other observers, we have sometimes found its treatment by trephining very disappointing, but not by any means always. We have noticed that some eminent ophthalmologists are so unfavourably impressed with decompression operations on the anterior segment that they consider repeated posterior sclerotomy the operation of choice in this affection. Posterior sclerotomy, as an operative treatment in any condition of the eye, has always seemed to us a remedy to be avoided if some less drastic procedure 
can be adopted. It was, therefore, with some satisfaction that we observed recently the effects of successful trephining on two cases of this malady, and we trust that a record of a somewhat unusual group of congenital glaucoma cases, suggesting familial sexlinked characters, may be of interest to others.

S. presented himself at the hospital on February 19, 1926, blind from buphthalmos. He was conducted by V., who showed the same condition but whose vision was moderately good. They said that there were two younger brothers and two elder sisters in the family. They were persuaded to have the brothers brought to hospital, but the sisters would not come. There did not seem to be much doubt that the sisters and parents had perfectly good vision. The brothers could not remember any instance of similar trouble amongst their relatives. Short notes of the cases of the four brothers prepared from details collected for us by Dr. P. A. Narayana Iyer of our staff, will sufficiently explain the more interesting features which we wish to present.

\section{Case I}

V., Hindu, male, aged 26 years, was admitted February 19, 1926, for dimness of vision and headache of three years duration.

R. V. $=6 / 36$, L. V. $=6 / 24$.

The pupils were moderately dilated and sluggish, the anterior chambers deep. The corneae looked large and measured in diameter $14 \mathrm{~mm}$. horizontally, $13 \mathrm{~mm}$. vertically. They were sharply marked off from the sclerae and did not show an overlap. The sclerae were not thinned out, the episcleral vessels were dark and prominent. The corneae were clear and did not show tears in Descemet's membrane. There was glaucomatous cupping on either side, and the tension, equal in each eye, was 80 (McLean). On March 18, 1926, the right eye was trephined; the left was treated by miotics. At the time of his discharge on April 21, 1926, the vision in the right eye was only counting fingers at 2.5 metres, the vision in the left still remained as before.

On June 30,1930 , he was readmitted.

R. V. $:=6 / 60$, with a $-3 \cdot 0$ D. sph. and a $-1 \cdot 0$ D. cyl. axis vert. $=6 / 6$.

L. V. = No perception of light.

The tension in the right eye was $13 \mathrm{~mm}$. $\mathrm{Hg}$ (Bailliart), that in the left 30 .

The right eye was quiet, filtration moderate, the cushion of filtration was well covered without any localized bleb formation. In the left eye the anterior chamber was much deeper, the lens was cataractous and appeared to be slightly sub-luxated backwards. The right field for a 2/2000 white object was approximately 
$10^{\circ}$ above, below and to the nasal side, and $20^{\circ}$ on the temporal side. Unfortunately it was not taken during his first admission.

In this case the trephining preserved the right eye which was slightly worse than the left at the time of operation. Although the tension in the right eye is still on the high side and the field is defective, the vision has remained good for five years at least after his decompression. Meantime the left eve, which may be regarded as a control, has been lost. The left eye was removed on August 5, 1930, and fixed in Zenker's fluid for further investigation. It is proposed to do a second trephining, or anterior decompression of some sort, on the right eye.

\section{Case II}

S., Hindu, male, aged 24 years, was admitted February 19, 1926 , with a history of defective sight for six years. Perception of light was not present in either eye. The tension in the right eye was 60 , that in the left 80 (McLean).

The corneae appeared large and measured $14 \mathrm{~mm}$. in their horizontal diameters. In the right eye the cornea showed a bluish haze with linear opacities. The anterior chamber was very deep, the pupil dilated and inactive. The globe was larger than normal. In the left eye the cornea was not so bluish and there were no defined opacities. The sclera was thinned out above near the limbus. The anterior chamber was deep and the pupil eccentric upwards. There was complete cupping of the optic discs.

On July 27, 1930, he was readmitted. There was no vision and the tension was $45 \mathrm{~mm}$. $\mathrm{Hg}$ (Bailliart) in either eye. There were cataractous changes and very marked opacities in the deeper layers of the cornea. Both eyes showed early staphylomatous changes near the limbus. In this case, hopeless from the time we saw him first, the condition was much more advanced than in that of his elder brother, and of longer duration.

\section{Case III}

K., Hindu, male, aged 19 years, was admitted March 6, 1926. R. V. $=6 / 5$. L. V. $=6 / 5$.

The corneae appeared clear and about normal in size, ther measured $12.5 \mathrm{~mm}$. in their horizontal diameters. The pupils were active and equal. The tension in either eye was $17 \mathrm{~mm}$. (Bailliart). There was physiological cupping. The fields were full on either side. With the corneal microscope nothing abnormal was observed in the deeper layers of the cornea. The lens showed fine opaque deposits about the anterior Y figure. 
On March 15, 1926, he was discharged and on July 23, 1930, readmitted in exactly the same condition.

The tension was now $10 \mathrm{~mm}$. $\mathrm{Hg}$ on either side (Bailliart). He had $6 / 5$ vision in each eye, a manifest hyperopia of $+1 \cdot 0 \mathrm{D}$. sph. with an accommodative power of $10 \mathrm{D}$. He was apparently normal when first seen and remained so.

\section{Case IV}

V., Hindu, male, aged 15 years, was admitted on March 6, 1926. R. V. $=6 / 5$. L. V. $=6 / 5$.

The corneae looked large and measured $14 \mathrm{~mm}$. in their horizontal diameters. There were no opacities nor were any deep changes seen with the corneal microscope. The fields were full for small white objects. The tension was equal on either side, $14 \mathrm{~mm}$. $\mathrm{Hg}$ (Bailliart). There was deep central cupping of both nerve heads.

On March 18, 1926, the right eye was trephined.

On April 21, 1926, the right eye vision was $6 / 5$, but there was hypotonus. He was discharged in this condition.

On July 22,1930 , he was readmitted.

R. V. $=6 / 5$. L. V. $:=6 / 5$.

The tension in the right eye was $13 \mathrm{~mm} . \mathrm{Hg}$, that in the left 35 mm. $\mathrm{Hg}$ (Bailliart).

There was a manifest hypermetropia of $1.0 \mathrm{D}$. each eye and the power of accommodation was $9.0 \mathrm{D}$. on either side. There was deep glaucomatous cupping. There were no corneal opacities or tears in Descemet's membrane.

With a $1 / 2000$ white object the right field was just within the $10^{\circ}$ circle, the left field within the $5^{\circ}$ circle.

In this case the trephined eye was in a very much better state four years after the operation than the eye which was not decompressed and which may be taken as a control. Apparently there is a slowly progressive deterioration of the right eye, and it is proposed to do a further decompression. The left eye was trephined on August 5, 1930.

Where the zonule has become so stretched, and in parts defective, that the vitreous invades the anterior chamber, trephining is not likely to succeed. At the time of writing this note, it was observed while trephining a child with well marked unilateral buphthalmos, that the fluid which escaped from the trephine hole was a thin watery vitreous fluid. It had not been remarked before the operation that there was anything of the kind present. Under chloroform a good ophthalmoscopic view had been obtained of the markedly cupped disc with a $-10 \mathrm{D}$. sphere. The lens seemed to be in good position. The pupil was comparatively small and 
active. The cornea measured $16.5 \mathrm{~mm}$. in diameter and showed diffuse and linear opacities, the centre was clear. The child would not permit of a corneal microscope examination, or the consistence of the fluid in the chamber might have been determined. The prognosis in this case is bad. In neither of the successful cases above recorded was the character of the aqueous fluid altered. The zonule presumably had not been so damaged by stretching as to allow of the vitreous (probably in such cases more fluid than normal), invading the anterior segment and mingling with the aqueous. After the removal of V's left eye (Case 1), when a fine radial cut was made through the cornea to allow better penetration of the fixative, a thin watery vitreous escaped. Evidently, since his previous visit to the hospital the zonule had become stretched and torn and the integrity of vitreous and aqueous interfered with. The success or failure of an anterior decompression must very largely depend on whether the normal relationship of aqueous and vitreous is preserved; and the changes which result in the zonule, and the vitreous body itself, as a result of stretching of the globe, eventually upset this relationship.

\section{ANNOTATIONS}

\section{Mr. Priestley Smith's Inaugural Address}

"For this do I honour my own profession." Religio Medici, 1, 13.

Those who have been so fortunate as to see the number of the Birmingham Medical Review for the month of October, 1930, must have thoroughly enjoyed reading the inaugural address, to the students in the medical faculty, delivered by Emeritus Professor Priestley Smith, LL.D., the doyen of British Ophthalmology. After commenting on his rashness in addressing a large concourse of students twenty years after the date of his retirement from active professorial work, Mr. Priestley Smith gives some interesting details of his own career as a student; comments in a delightful manner on what must surely be endemic among boys who have just left school, viz., " no urgent desire for further work of any kind"; recalls how he began life as an engineer, in which profession he served a four years' apprenticeship; how he took up medicine, later in life than the average medical student, when he was nearly twenty-two years of age; and finally how he has never regretted his choice of a profession.

His address followed on customary lines and contains much good advice to those who are entering the medical profession. We 